\title{
Phylogeography of Myrica nana: the Wumeng Mountains as a natural geographical isolation boundary on the Yunnan-Guizhou Plateau
}

\author{
Zhao $\mathrm{Cai}^{1}$ \\ ${ }^{1}$ Guizhou University
}

December 1, 2021

\begin{abstract}
The Yunnan-Guizhou Plateau (YGP) is characterized by the distinctive isolated habitat of limestone Karst Islands and features the Wumeng Mountains (Mts), which divide the YGP into the two Plateaus of Yunnan and Guizhou. This study aims to assess the effects of past geographic and environmental isolation and climate fluctuation on the flora distribution in the YGP. To this effect, we analyzed the phylogeographical pattern and genetic structure for Myrica nana, a vulnerable species endemic to the YGP, based on chloroplast and nuclear ribosomal DNA sequence. The results suggest that the genetic and haplotype network structures are divided into at least two groups - cpDNA haplotype H2 (or nrDNA haplotypes h1, h2, and the native haplotype) mainly distributed to the east of the Wumeng Mts, and cpDNA haplotype H1 and haplotypes H3-H10 (or nrDNA haplotype h3) distributed to the west of the Wumeng Mts. A deep genetic split was noted within the two groups to reach 25 steps, especially for the cpDNA fragment variation. The east-west divergence reveals the existence of a natural geographical isolation boundary in the form of the Wumeng Mts, which divides the YGP into the Yunnan and Guizhou Plateaus. Therefore, there existed at least two glacial refugia during the Quaternary glacial period, along with a genetic diversity center, and at least two large geographic protection units for the vulnerable species of M. nana, distributed throughout the eastern and western sides of the Wumeng Mts. This study not only clarifies that the phylogeographical pattern and genetic structure for M. nana can be attributed to geographic and environmental isolation and climate fluctuation, but it also proposes an effective strategy to protect vulnerable species and the important wild flora of the YGP.
\end{abstract}

\section{Hosted file}

Manuscript.docx available at https://authorea.com/users/448806/articles/547527phylogeography-of-myrica-nana-the-wumeng-mountains-as-a-natural-geographical-isolationboundary-on-the-yunnan-guizhou-plateau

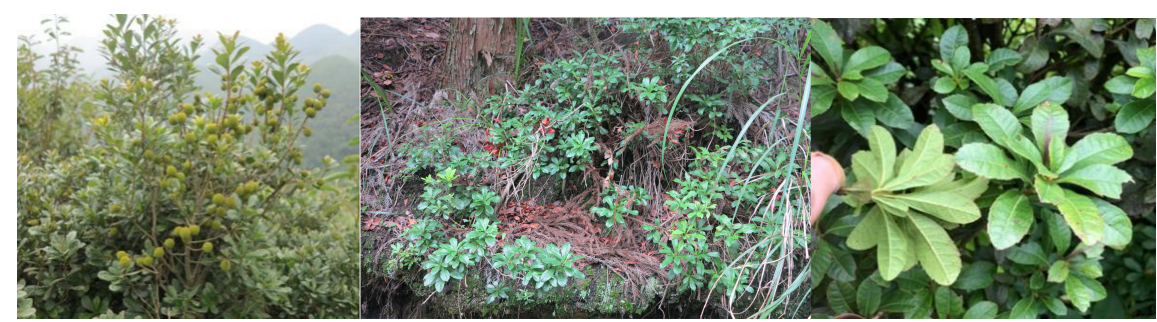



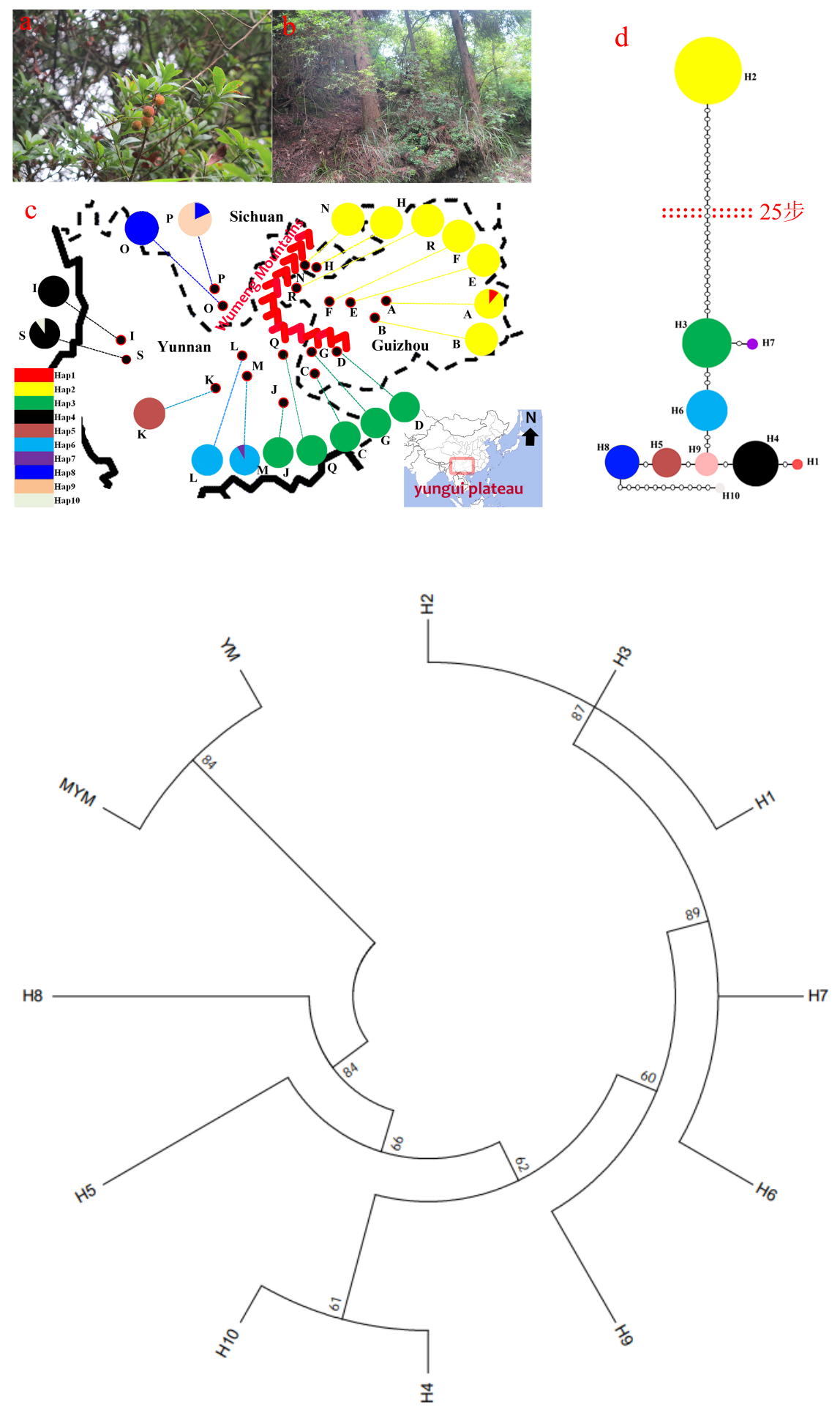

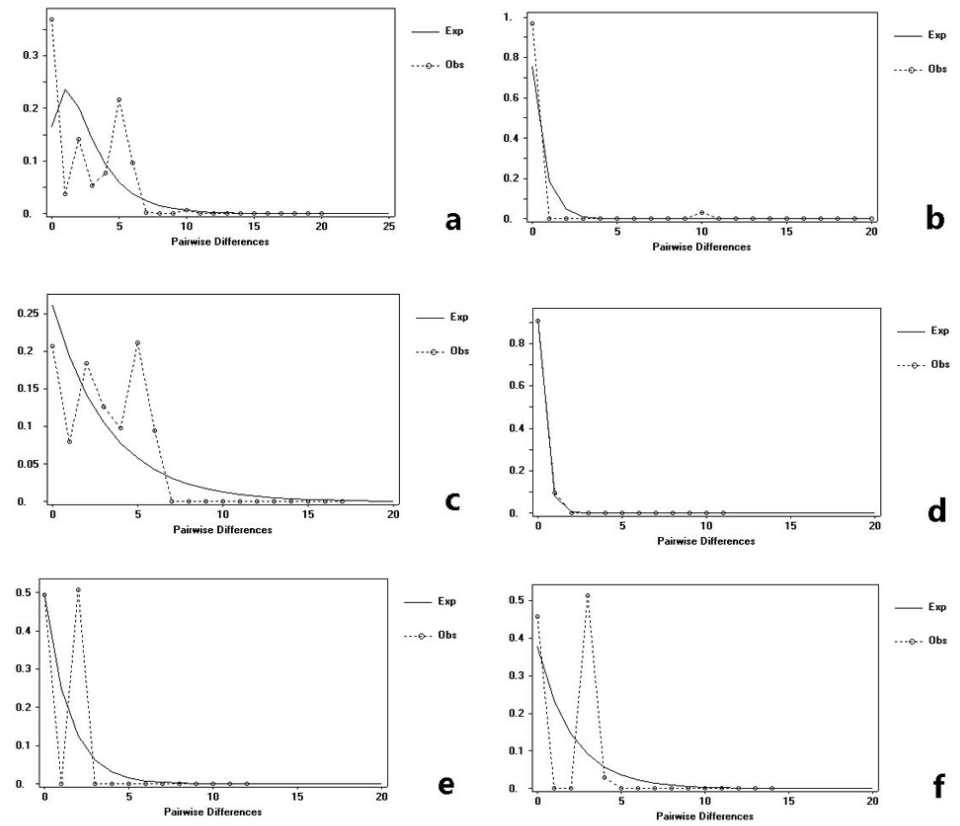

a



b

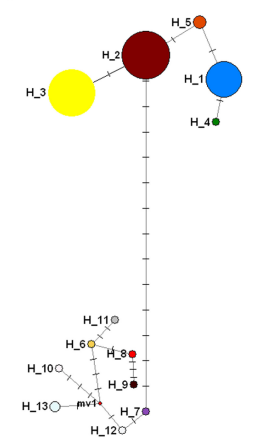



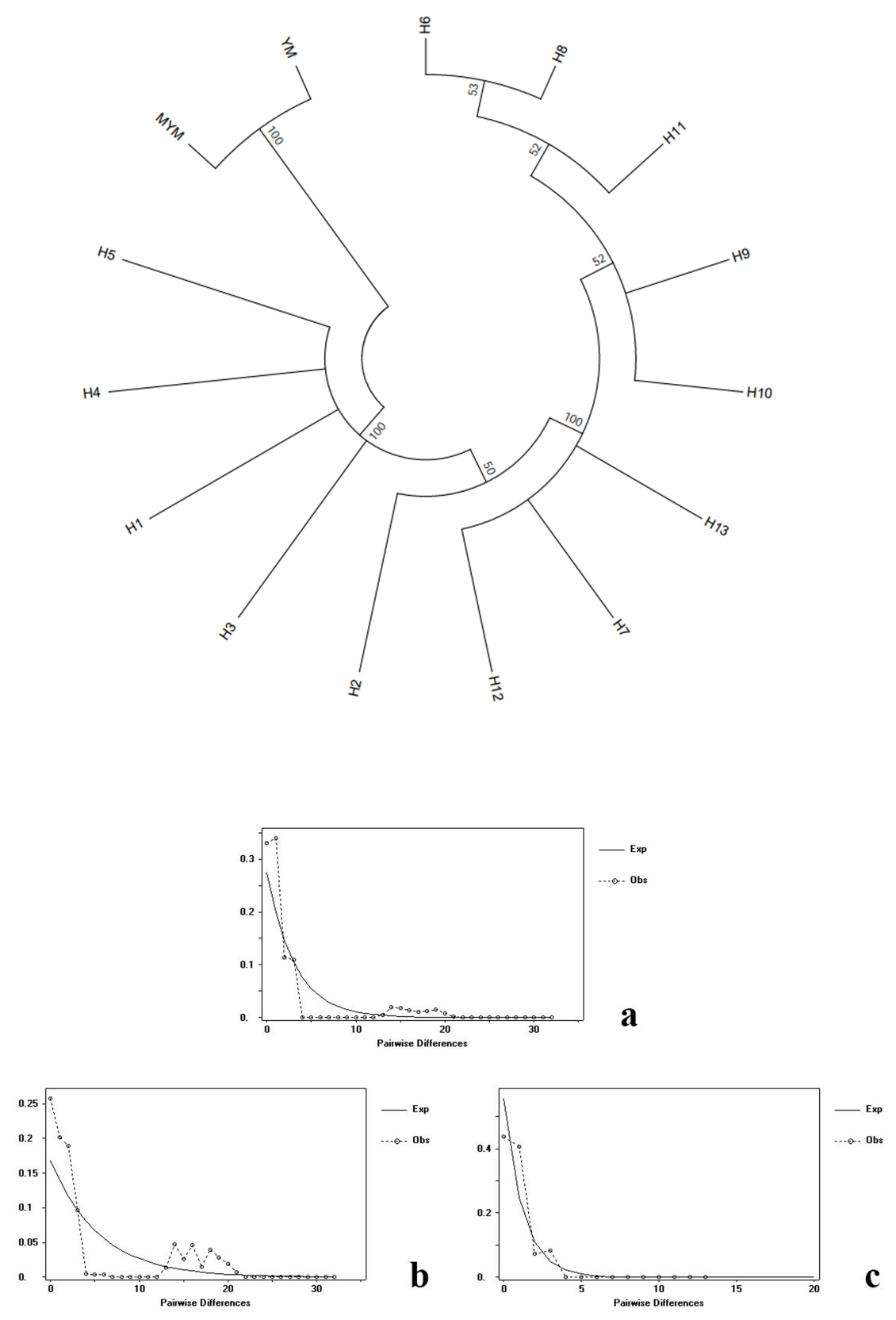